\title{
Childhood Obesity, Unrecognized Public Health Challenge in Nepal
}

Aryal M

Most of emphasis in the past years had been allotted to alleviation of poverty and undernutrition in the children of Nepal. The concept of being bigger is healthier had been the conviction among the population. But it is being obliterated gradually in most part of the world because of rapid emergence of childhood obesity in the last two decades. The childhood obesity has now recognized as a global health problem because of its devastating consequences and its prevalence is escalating at uncontrollable rate worldwide. In 2010, forty three million children (thirty five million in developing countries) were estimated to be overweight and obese; ninety two million were at risk of overweight. The worldwide prevalence of childhood overweight and obesity increased from four percent in 1990 to six percent in the year 2010. ${ }^{1}$ This trend is expected to reach nine percent or approximately sixty million, in 2020. Although, the prevalence is comparatively lower in Asia (4.9\% in 2010), the number of afflicted children are greater. ${ }^{1}$ The population based studies in the neighbouring countries like China and India revealed the increased trend of childhood overweight and obesity. ${ }^{2,3}$ To date there is no information on the extent of affliction due to overweight and obesity among children in Nepal. Although several nationally representative nutrition surveys have been conducted, ${ }^{4}$ their focus was on underweight and rates of overweight and obesity rarely were reported.

No doubt, childhood obesity is global health concern affecting all socio-economic groups, irrespective of age, sex or ethnicity. Aetiopathogenesis of childhood obesity is multi-factorial and includes genetic, neuroendocrine, metabolic, psychological, environmental and socio-cultural factors. But it is particularly prevalent in areas that has gone through rapid economic growth, industrialization, urbanization, mechanization, cultural transition, and commodification of food systems. The studies have shown strong association of chidlhood obesity with family history, sedentary life style, socoeconomic status, televesion watching and internets, computer games, eating behahivor, sleeping patterns etc. ${ }^{1,5}$ With the discernible transformation of Nepalsese society towards rapid urbanization, mechanization, life style and dietary modification it can be hypothesized that the burden of the disease may be mounting in Nepal as well.

Even though the health consequences of obesity are most commonly seen during adulthood, the underlying factors of these diseases could originate during childhood. Researchers showed an association between obesity in childhood and high prevalence of blood pressure, diabetes, respiratory disease, and orthopedic and psychosocial disorders. ${ }^{6}$ Cardiovascular diseases and diabetes are two chronic diseases which are rapidly increasing globally with no exception to Nepal. ${ }^{7}$ If the proper attention is not allotted in the prevention and treatment of childhood obesity, it may cause devastating consequences among the population with large spending on the treatment of the complications associated with childhood obesity in the near future.

It is, therefore, vital to know the prevalence, etiology and risk factors and consequences associated with childhood obesity in our population, if this public health cri- 
sis is to be addressed successfully. So, it is of our prime necessity to assess the burden of the disease and the associated risk factors in our population. Furthermore, we should collaborate with governmental and non-governmental organization to instigate school-based educative program emphasizing on dietary management, physical activity enhancement, and restriction of sedentary behavior. We must be particular in addressing the problem of childhood obesity before it turns into epidemic. Prevention is better than cure.

\section{REFERENCES}

1. de Onis M, Blössner M, Borghi E.Global prevalence and trends of overweight and obesity among preschool children. Am J Clin Nutr 2010;92:1257-64.

2. Cui Z, Huxley R, Wu Y, Dibley MJ. Temporal trends in overweight and obesity of children and adolescents from nine Provinces in China from 1991-2006. Int J Pediatr Obes 2010;5:365-74.

3. Raj M, Sundaram KR, Paul M, Deepa AS, Kumar RK. Obesity in Indian children: time trends and relationship with hypertension. Natl Med J India 2007;20:288-93.

4. Gelal B, Aryal M, Das BKL, Bhatta, Lamsal M and Baral N. Assessment of iodine nutrition status among school children of Nepal by urinary iodine assay. Southeast Asian J Trop Med Public Health 2009;40:538- 43.

5. Strauss RS, Pollack HA. Epidemic increase in childhood overweight, 1986-1998. JAMA 2001;286:2845-8.

6. Dietz WH. Overweight in childhood and adolescence. N Engl J Med. 2004;350:855-7.

7. Aryal M, Jha B. Proteinuria as the marker of diabetic nephropathy. Nepal Med Coll J 2006;8:250-3. 